\title{
Que faire des poètes (2)?
}

C haque fois que je passe quelques jours à Paris, je suis émerveillé par la sensibilité des Français à la Poésie. Il y a chez eux, d'ailleurs, un certain respect, une admiration incontestable pour le Poète.

Quelle autre nation aurait donné des noms de poètes nationaux à deux de ses formations militaires? Quel beau message de paix et de liberté a resonné dans le monde entier lorsque, l'été dernier, les deux colonnes, Baudelaire et Rimbaud, ont pénétré le territoire divisé, ensanglanté du Kosovo!

Marchez dans les rues de Paris et l'oeil s'arrête devant un panneau où chante une ballade d'un poète contemporain. De la publicité qui ne se vend pas et qui ne vend pas. Elle éveille la conscience. Généreuse, gratuite, elle célèbre un nom et offre une pause momentanée, une oasis de vert et de calme, à notre quotidien urbain de bousculades et de stress, souvent stérile.

Pareil dans le métro, l'oeil scande des vers et le rythme fait oublier le bruit des rails et les visages éreintés des passagers. On est dépaysé du tunnel vers un prés de vert, vers une eau fraîche, vers une source d'enfance, un lit de souvenirs, dans les bras d'une figure d'amour. Soudain, inattendu, ce don, - lui aussi gratuit, généreux - le sourire qui s'ébauche aux lèvres.

Ce printemps dernier le plaisir a été particulier, spécial, parce que sur les panneaux des rues, des métros, des jardins s'affichaient même des voix transatlantiques, de notre Québec. Deux peuples, une langue, réunis par un pont d'élans poétiques.

J'ai visité aussi, au mois de juin, les étalages du Marché de la Poésie, sur la Place Saint Sulpice, à l'ombre de ses deux clochers et autour de sa fontaine. Ici c'est la fête, c'est la foire, c'est le marché. Ici la poésie c'est le livre, c'est l'affiche, c'est le récital, c'est la chanson... De tous les coins de France, comme des fleuves qui convergent, l'imaginaire poétique s'est rassemblé sur cette Place, concrétisé dans toute sa diversité, dans toute sa richesse.

Par contre, quelle réserve on rencontre chez nous, en Amérique du Nord! On dirait qu'on a honte de la poésie. On la cache. Les Américains sont un peu moins timides, un peu plus démonstratifs que les Canadiens. Eux, aux moins, ils ont un bard national. Et le Newshour du reseau télévisif public PBS inclut de temps en temps une lecture du ce poète honoré, actuellement Robert Pinsky. C'est exceptionnel, car d'habitude le poète chez nous bredouille son nom, le murmure; il se désigne poète tout en s'excusant de l'être. Il est considéré un excentrique et ce qu'il fait l'inutile même.... dommage, ce signe de pauvreté de notre état culturel! 
Üzeyir Lokman Çayci, poète et artiste, est né à Bor en Turquie et vit à Mantes La Ville en France.. Il détient un diplôme d'architecte d'intérieur et de concepteur industriel. Ses travaux pleins d'originalité n'ont pas tardé à attirer l'attention des connaisseurs. Ses poèmes et ses nouvelles ont été publiées dans divers revues et journaux. Son recueil de poésie L'Arrêt des Soirs a été publié en 1975.

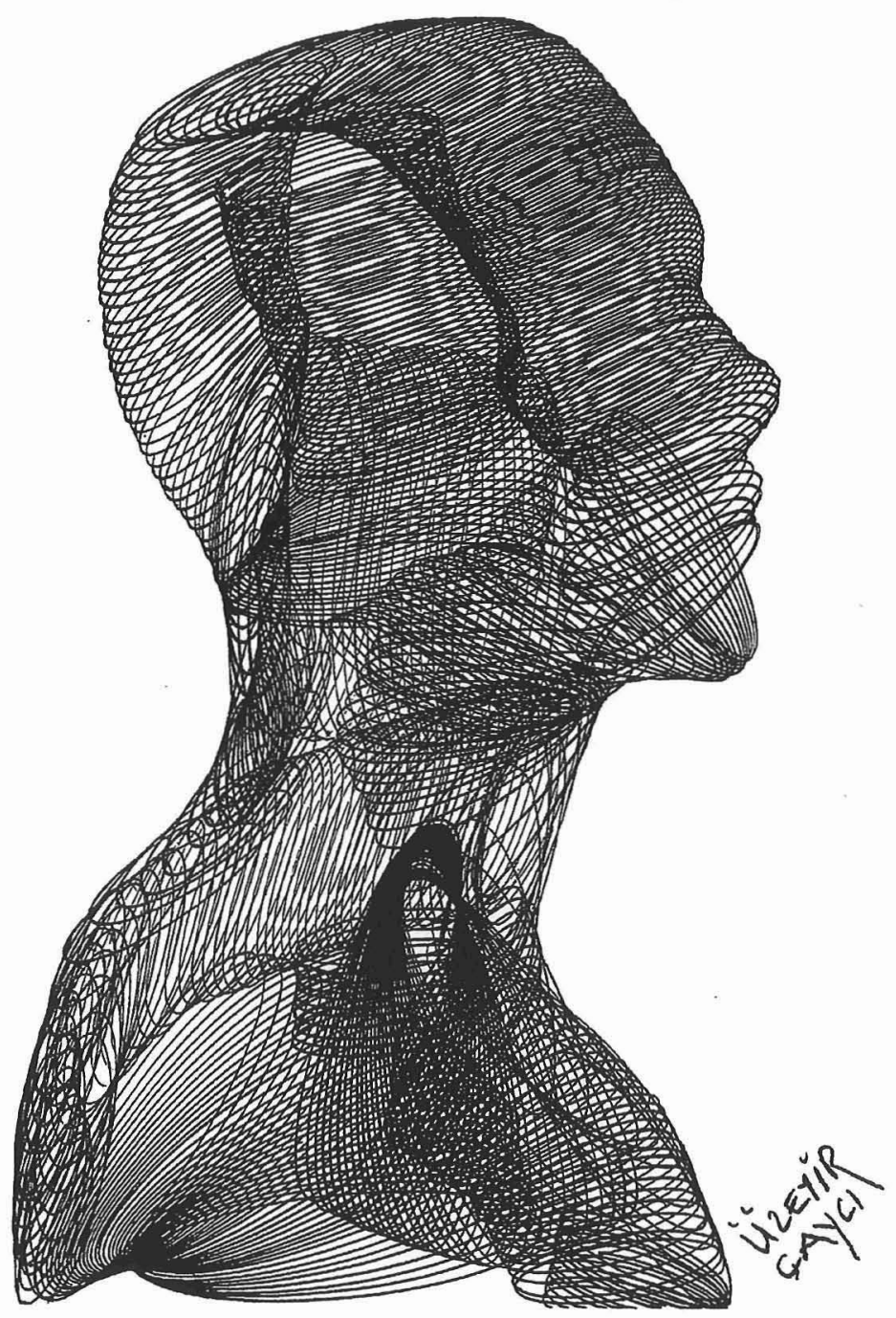

